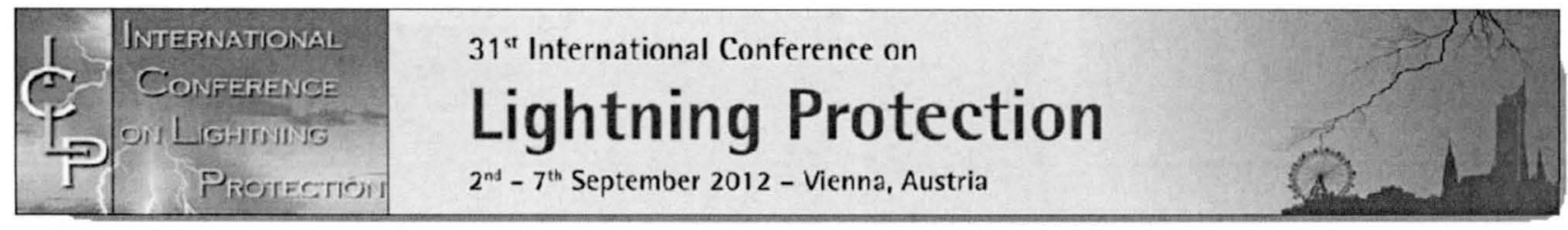

\title{
ICLP 2012 \\ SUMMARY OF 2011 DIRECT AND NEARBY LIGHTNING STRIKES TO LAUNCH COMPLEX 39B, KENNEDY SPACE CENTER, FLORIDA
}

\author{
C.T. Mata, A.G. Mata \\ ESC, Kennedy Space Center, Florida, USA. \\ E-mail: carlos.t.mata@nasa.gov, angel.g.mata@nasa.gov
}

\begin{abstract}
A Lightning Protection System (LPS) was designed and built at Launch Complex 39B (LC39B), at the Kennedy Space Center (KSC), Florida in 2009. This LPS was instrumented with comprehensive meteorological and lightning data acquisition systems that were deployed from late 2010 until mid 2011. The first direct strikes to the LPS were recorded in March of 2011, when a limited number of sensors had been activated. The lightning instrumentation system detected a total of 70 nearby strokes and 19 direct strokes to the LPS, 2 of the 19 direct strokes to the LPS had two simultaneous ground attachment points (in both instances one channel terminated on the LPS and the other on the nearby ground). Additionally, there are more unaccounted nearby strokes seen on video records for which limited data was acquired either due to the distance of the stroke or the settings of the data acquisition system. Instrumentation deployment chronological milestones, a summary of lightning strikes (direct and nearby), high speed video frames, downconductor currents, and $\mathrm{dH} / \mathrm{dt}$ and $\mathrm{dE} / \mathrm{dt}$ typical waveforms for direct and nearby strokes are presented.
\end{abstract}

\section{INTRODUCTION}

The installation of the lightning instrumentation system at Launch Complex 39B (LC39B) started in March 2011 and was completed in May 2011. The triggering thresholds were adjusted based on previous Camp Blanding testing using the same instrumentation to detect strikes within the LC39B perimeter and nearby strikes (close to the pad) as predicted $\mathrm{dH} / \mathrm{dt}$ and $\mathrm{dE} / \mathrm{dt}$. During the previous to last Shuttle Launch (STS-134) the triggering thresholds of the system were reduced in an attempt to detect potential lightning strikes at Launch Complex 39A (LC39A), where Endeavor was being prepared to launch. The thresholds were lowered since Endeavour rolled out (March 10 2011) until shortly after launch (May 16, 2011). A few storms passed through the area and many images of nearby strikes were captured with some limited number of waveforms with usable data were acquired. Note that the dynamic range of the measurements were not changed, so the majority of the waveforms for nearby strikes had very poor resolution. Shortly before the roll out of the last Space Shuttle mission (Atlantis, STS-135, May 31 2011), a trigger signal from LC39A was fed into the LC39B lightning instrumentation system (June 21, 2011), in an attempt increase the LC39B lightning instrumentation triggering thresholds and reduce the number of flashes detected to those of interest only (strikes to either LC39A or LC39B). This trigger signal from LC39A to LC39B was left in place even after Atlantis launched in July 8, 2011. The lightning instrumentation system at LC39B helped determine the location of strikes nearby LC39A during some storms prior to launch and even a strike within the LC39A perimeter the day before launch, preventing a potential launch scrub that would have delayed the mission and resulted in additional costs.

\section{INSTRUMENTATION OVERVIEW AND SETUP}

The LC39B LPS and its instrumentation are described in detail in [1] and [2], respectively. The LPS can be seen as two independent, but synchronized, data acquisition systems, Lightning and Weather [3], both running 24/7. In general, the LPS consists of a catenary wire system (at about 181 meters above ground level) with nine downconductors connected to ground, supported by three insulators installed atop three towers in a triangular configuration. Field sensors' signals are digitized and transmitted, via fiber optics, to centralized transient recorders located in the Pad Termination Connection Room (PTCR). All the LPS instrumentation, including the digitizers, transient recorders, and computers, are battery backed up.

\subsection{Lightning Instrumentation}

This is an event driven, $100 \mathrm{MS} / \mathrm{s}$ sampling system, which includes six synchronized high-speed video cameras installed atop each of the three towers (two per tower) and one remote high-speed video camera installed about five kilometers southwest of LC39B (temporarily installed in the firing room 1 of the Launch Control Center (LCC) pending final installation atop the Vehicle Assembly Building (VAB)). Current sensors installed at ground level on each of the nine downconductors of the LPS; four $\mathrm{dH} / \mathrm{dt}$, 3-axis measurement stations; and five $\mathrm{dE} / \mathrm{dt}$ stations composed of two antennas each. The electromagnetic sensors are all installed at ground level with elevations 
ranging from 5.9 to 7.4 meters height referred to the North American Vertical Datum of 1988 (NAVD88). All these signals are recorded using three synchronized transient recorders (HBM GENESIS 16t).

The trigger signal for the LC39B LPS instrumentation system comes from any of the thirty one ground level sensors ( 9 downconductor currents, $12 \mathrm{dH} / \mathrm{dt}, 10 \mathrm{dE} / \mathrm{dt}$ ), additionally a TTL signal from the LC39A lightning instrumentation system is provided. After a qualified trigger is received, the signal of all the ground level sensors is recorded on a $30 \mathrm{~ms}$ time window with $50 \%$ pre-trigger sampling at $100 \mathrm{MS} / \mathrm{s}$. Additionally, the seven high speed video cameras record up to 455 frames with 312.5 us exposure (up to $142.1 \mathrm{~ms}$ of video at $3,200 \mathrm{fps}$ ) with a resolution of $1280 \times 800$, also with $50 \%$ pre-trigger. The VAB camera, overlooking both LC39A and LC39B has twice the memory and twice the sampling rate as the cameras at LC39B, while maintaining the resolution and the acquisition window. This camera is expected to be operational in February 2012.

\subsection{Meteorological Instrumentation}

This meteorological instrumentation is a $24 / 7,1$ sample/s, system, which provides air temperature, relative humidity, wind direction and wind speed at four different altitudes (40.2, 78.3, 116.4 and 139.3 meters), on each of the four levels (A, B, C, and D) of the three LC39B lightning protection towers. Also, the meteorological instrumentation has two rain gauges (at ground level) that measure rain precipitation and accumulation, adding to a total of 26 weather sensors ( 24 distributed among the four levels of the three towers and 2 at ground level).

The Meteorological data is displayed on the internal KSC TV system, showing the one-minute running average of all the measurements in addition to the maximum wind gust and wind direction over the last minute. Additionally, the meteorological data will be transmitted to the $45^{\text {th }}$ Weather Squadron (CCAFS, Florida) to support weather related launch decisions.

\section{CHRONOLOGICAL MILESTONES}

The data acquisition capability of the LPS at LC39B has been incrementally increasing after its construction. Table I shown remarkable milestones worth noting.

Table I: LPS chronological milestones.

\begin{tabular}{l|r}
\hline Action & $\begin{array}{r}\text { Time } \\
\text { (year) }\end{array}$ \\
\hline Conceptual Design & 2007 \\
\hline Construction & $2008-2009$ \\
\hline $\begin{array}{l}\text { Instrumentation Enclosure fabrication, } \\
\text { testing and installation }\end{array}$ & 2010 \\
\hline DAQ installed & Jan. 2011 \\
\hline $\begin{array}{l}\text { All (8) Tower 1 meteorological stations } \\
\text { active }\end{array}$ & Feb. 2011
\end{tabular}

\begin{tabular}{|c|c|}
\hline $\begin{array}{l}\text { All (9) downconductors instrumentation, } \\
\text { towers } 2 \& 3 \text { meteorological stations and } 2 \\
\text { (out of } 6 \text { ) high speed video cameras active }\end{array}$ & Mar. 2011 \\
\hline $\begin{array}{l}\text { First and last nearby lightning strike } \\
\text { recorded }\end{array}$ & $\begin{array}{r}\text { Mar. } 30^{\text {th }} \& \\
\text { Oct. } 10^{\text {th }} \\
(2011) \\
\end{array}$ \\
\hline $\begin{array}{l}\text { First and last direct lightning strike } \\
\text { recorded }\end{array}$ & $\begin{array}{r}\text { Mar. } 31^{\text {th }} \& \\
\text { Aug. } 14^{\text {th }} \\
(2011) \\
\end{array}$ \\
\hline $\begin{array}{l}4 \text { (out of 6) high speed camera and all (12) } \\
\text { magnetic field measurements active }\end{array}$ & Apr. 2011 \\
\hline $\begin{array}{l}\text { All (6) high speed video cameras and all } \\
\text { (10) electric field measurements }{ }^{1} \text { active }\end{array}$ & May 2011 \\
\hline $\begin{array}{l}\text { Meteorological data shown on OTV, } \\
\text { additional trigger signal from LC39A and } \\
\text { additional (temporary) high speed video } \\
\text { camera in LCC }\end{array}$ & June 2011 \\
\hline 1 (out of 2) rain stations active & Aug. 2011 \\
\hline All (2) rain stations active & Sep. 2011 \\
\hline
\end{tabular}

\section{ACQUIRED DATA, LIGHTNING}

The Lightning DAQ was active from mid-March of 2011.

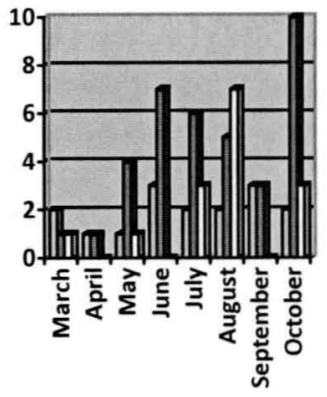

From March to October 2011:

The Lightning DAQ has triggered on 16 different days

a) Direct: The LPS has been struck directly by 8 lightning flashes (all towers have been struck):

a. 5 flashes attached to the towers

b. 3 flashes attached to the catenary wires or downconductors

c. 3 single-stroke flashes

d. 5 multi-stroke flashes ( $\max .8 \mathrm{RS}$; $\min$. 2RS)

e. Only one multi-stroke (3RS) flash had all subsequent RS terminating at the same location as the first RS

b) Close nearby (within the LC39B perimeter fence): There have been 3 nearby lightning strikes within the LC39B perimeter

a. 1 strike to the perimeter fence (multistroke flash, 4 RS)

\footnotetext{
1 From May until July there were some electric field measurements troubleshooting, so, partial (or no) $\mathrm{dE} / \mathrm{dt}$ measurements would be available for this period.
} 
b. 2 inside the perimeter (single-stroke flashes)

c) Nearby The LPS was subject to 40 nearby (only) lightning flashes:

a. 2 nearby strikes happened simultaneously with direct strikes

b. 26 single-stroke flashes

c. 14 multi-stroke flashes ( $\max .6 \mathrm{RS}$; min. 2 RS)

d. X triggered by LC39A; Y triggers by LC39A with no evidence of lightning

e. Nearby channels with multiple termination points?

There have been 2 lightning strikes with two simultaneous ground attachment points (see Figure 1), tower 2 and nearby (outside the LC39B perimeter fence).

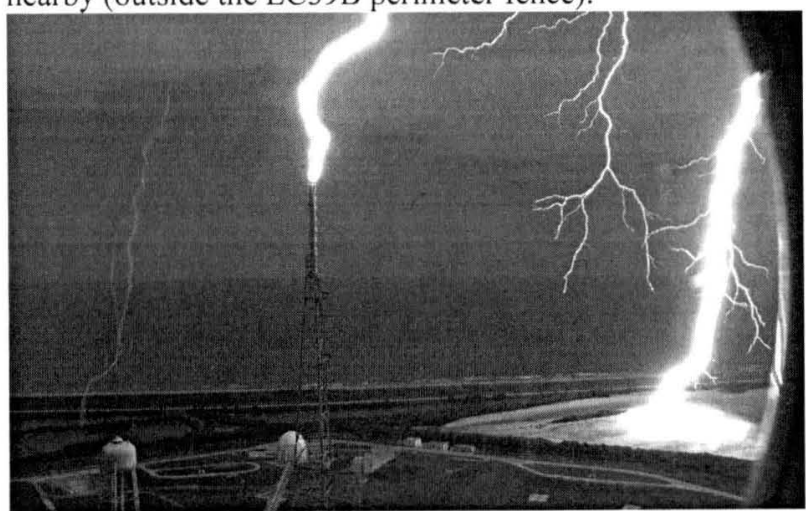

Figure 1. Strike to Tower 2 of the LC39B Lightning Protection System with two simultaneous attachment points, one to Tower 2 and the other to the ground southeast of LC39B, just outside the pad fence.

\subsection{Statistics}

\subsection{Selected Waveforms}

\subsubsection{Direct Lightning Strokes}

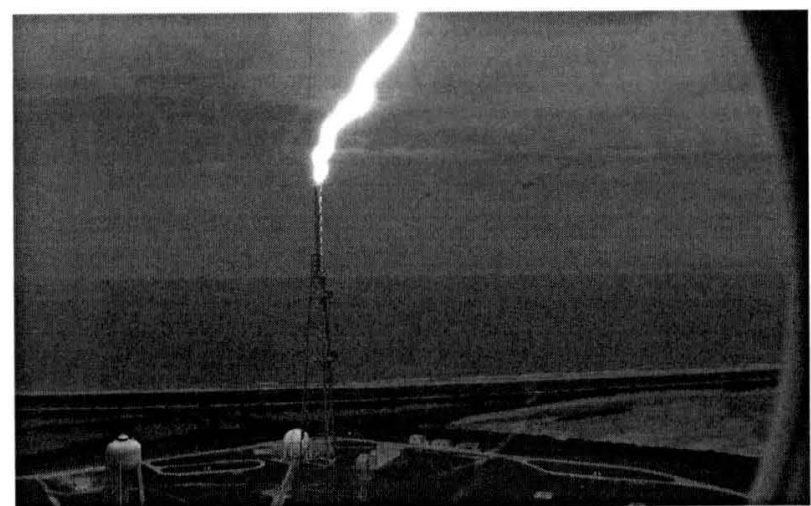

Figure 2. Direct lightning strike to Tower 2 of the LC39B lightning protection system.

\subsubsection{Nearby Lightning Strokes}

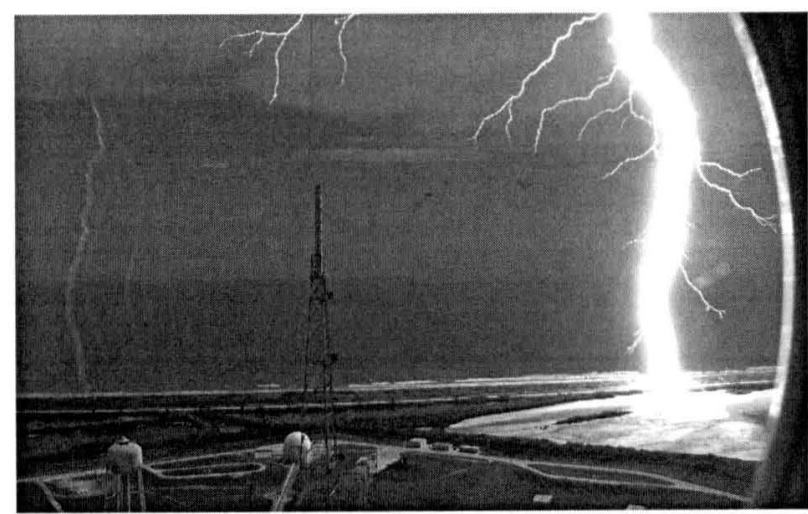

Figure 3. Nearby strike southeast of Tower 2 of the LC39B lightning protection system.

\subsection{Selected High Speed Video camera data}

\section{CONCLUSIONS}

After less than one year of deployment, the new lightning instrumentation system at $\mathrm{LC} 39 \mathrm{~B}$ has shown significant improvements over the previous lightning instrumentation system used at KSC. The instrumentation system has proven to be reliable and very accurate, acquiring a series of astonishing images and set of waveforms for typical and unusual lightning strikes. There is an increased interest to potentially deploy similar systems throughout KSC and the Cape Canaveral Air Force Station, in which case there may be a comprehensive an integrated lightning observation system with synchronized lightning instrumentation over an area of several square miles.

\section{REFERENCES}

[1] C.T. Mata, V.A. Rakov, "Evaluation of lightning incidence to elements of a complex structure: a Monte Carlo approach," International Conference on Grounding and Earthing \& $3^{\text {rd }}$ International Conference on Lightning Physics and Effects (Ground 2008; $3^{\text {rd }}$ LPE), Florianopolis, Brazil, November 2008.

[2] C.T. Mata, V.A Rakov, T. Bonilla, A.G. Mata, E. Navedo, G.P. Snyder, "A new comprehensive lightning instrumentation system for PAD 39B at the Kennedy Space Center, Florida" International Conference on Lightning Protection 2010, Cagliari, Italy, September 2010.

[3] C.T. Mata, A.G. Mata, V.A. Rakov, "A New Lightning Instrumentation for Pad 39B at the Kennedy Space Center, Florida, Oral Presentation, American Meteorological Society $91^{\text {st }}$ Annual Meeting, Seattle, USA, January 2011. 